\title{
Isotope Effect and Lanthanide Contraction for 3d-4f Cyanide-Bridged Complexes Exhibiting Negative Thermal Expansion
}

\author{
Yusuke Kimoto, Takeshi Matsui and Takashiro Akitsu*
}

Department of Chemistry, Faculty of Science, Tokyo University of Science, 1-3 Kagurazaka, Shinjuku-ku, Tokyo 162-8601, Japan

\begin{abstract}
We have prepared some 3d-4f cyanide-bridged $\mathrm{Ln}(\mathrm{DMF})_{4}\left(\mathrm{H}_{2} \mathrm{O}\right)_{3} \mathrm{Fe}(\mathrm{CN})_{6} \cdot \mathrm{H}_{2} \mathrm{O}$ complexes $(\mathrm{Ln}=\mathrm{Ce}, \mathrm{Sm}, \mathrm{Nd}$, and $\mathrm{Gd} ; \mathrm{DMF}=\mathrm{N}, \mathrm{N}$-dimethylformamide) by substituting isotopes to ${ }^{2} \mathrm{H}$-substituted $\mathrm{H}_{2} \mathrm{O}$ and DMF and ${ }^{18} \mathrm{O}$-substituted $\mathrm{H}_{2} \mathrm{O}$ (and normal ${ }^{1} \mathrm{H}$ - and ${ }^{16} \mathrm{O}-\mathrm{H}_{2} \mathrm{O}$ or ${ }^{1} \mathrm{H}-\mathrm{DMF}$ ). We examined their crystal structures exhibiting negative thermal expansion and compared in view of hydrogen bonds and lanthanide contraction. Magnetic properties and thermal analysis exhibited importance of intermolecular hydrogen bonds in crystal lattice for this behavior. While Fe2 $\mathrm{p}_{3 / 2}$ and Fe2 $\mathrm{p}_{1 / 2} \mathrm{XAS}$ indicated constant inner shell electron states of low-spin Fe(III) ions.
\end{abstract}

Keywords: Negative thermal expansion, cyanide, isotope, lanthanide.

\section{INTRODUCTION}

Recently, various $3 \mathrm{~d}-4 \mathrm{f}$ molecule-based magnets such as $\mathrm{Ln}(\mathrm{DMF})_{4}\left(\mathrm{H}_{2} \mathrm{O}\right)_{3} \mathrm{M}(\mathrm{CN})_{6} \cdot \mathrm{H}_{2} \mathrm{O}$ have been investigated widely $[1,2]$. The first photo-controllable $3 \mathrm{~d}-4 \mathrm{f}$ moleculebased magnets was $\mathrm{Nd}(\mathrm{DMF})_{4}\left(\mathrm{H}_{2} \mathrm{O}\right)_{3} \mathrm{Fe}(\mathrm{CN})_{6} \cdot \mathrm{H}_{2} \mathrm{O}$ [3], and its crystal structure of photo-excited state was also determined [4]. Besides magnetic properties, we have systematically studied on $\operatorname{Ln}(D M F)_{4}\left(\mathrm{H}_{2} \mathrm{O}\right)_{3} \mathrm{M}(\mathrm{CN})_{6} \cdot \mathrm{H}_{2} \mathrm{O}$ and related compounds in view of structure-function correlation due to lanthanide contraction and application for hybrid functional materials [5].

Previously, we found that isotope effects of temperature dependence of magnetization for $\mathrm{Nd}(\mathrm{DMF})_{4}\left(\mathrm{H}_{2} \mathrm{O}\right)_{3}$ $\mathrm{Fe}(\mathrm{CN})_{6} \cdot \mathrm{H}_{2} \mathrm{O}$ with ${ }^{2} \mathrm{H}$-substituted $\mathrm{H}_{2} \mathrm{O}$ and DMF ligands [6]. Since crystal structure was not determined for them, we investigated TG-DTA for intermolecular hydrogen bonds in crystal lattice and ${ }^{57} \mathrm{Fe}$ Mössbauer spectra and $\mathrm{Fe} 2 \mathrm{p}_{3 / 2}$ and $\mathrm{Fe} 2 \mathrm{p}_{1 / 2}$ XAS for coordination environment or electronic states of $\mathrm{Fe}$ (III) ions. The experimental results suggested that intermolecular hydrogen bonds was important for this isotope effects found in $\mathrm{Nd}(\mathrm{DMF})_{4}\left(\mathrm{H}_{2} \mathrm{O}\right)_{3} \mathrm{Fe}(\mathrm{CN})_{6} \cdot \mathrm{H}_{2} \mathrm{O}$.

In order to discuss crystal structure directly, we examined temperature dependence of cell parameters for $\mathrm{Nd}(\mathrm{DMF})_{4}$ $\left(\mathrm{H}_{2} \mathrm{O}\right)_{3} \mathrm{Fe}(\mathrm{CN})_{6} \cdot \mathrm{H}_{2} \mathrm{O}$ (hereafter abbreviation of LnFeXY denotes Ln-Fe binuclear complexes ( LnFe) employing ${ }^{1} \mathrm{H}_{2} \mathrm{O}$ (H), ${ }^{2} \mathrm{H}_{2} \mathrm{O}(\mathbf{D})$, and $\mathrm{H}_{2}{ }^{18} \mathrm{O}(\mathbf{O})$ for $\mathbf{X}$ and ${ }^{1} \mathrm{H}-\mathrm{DMF}(\mathbf{H})$ and ${ }^{2} \mathrm{H}-\mathrm{DMF}$ (D) for $\mathbf{Y}$ ) and determined crystal structures at some points. Additionally, we also compared with $\mathrm{CeFeXY}$, SmFeXY, and GdFeXY complexes for crystal structures and several physical properties. Anisotropic negative thermal expansion [7-10] has been found for these $\mathrm{Ln}(\mathrm{DMF})_{4}\left(\mathrm{H}_{2} \mathrm{O}\right)_{3}$ $\mathrm{M}(\mathrm{CN})_{6} \cdot \mathrm{H}_{2} \mathrm{O}$ complexes and will be discussed novel

*Address correspondence to this author at the Department of Chemistry, Faculty of Science, Tokyo University of Science, 1-3 Kagurazaka, Shinjukuku, Tokyo 162-8601, Japan; Tel: +81-3-5228-8271; Fax; +81-3-5261-4631; E-mail: akitsu@ @rs.kagu.tus.ac.jp flexibility of crystal lattices compared with previously found flexible Jahn-Teller distortion of $\mathrm{Cu}(\mathrm{II})$ complexes [11, 12].

\section{MATERIALS AND METHODOLOGY}

\section{General Procedure}

Chemicals and solvents of the highest commercial grade available (Kanto Chemical, Tokyo Chemical Industry, and Wako) were used as received without further purification.

\section{Preparations}

$\mathrm{Ln}(\mathrm{DMF})_{4}\left(\mathrm{H}_{2} \mathrm{O}\right)_{3} \mathrm{M}(\mathrm{CN})_{6} \cdot \mathrm{H}_{2} \mathrm{O}$ were prepared in a similar way to the analogous compounds $[1,2]$ by employing the corresponding metal sources and solvents substituted by the corresponding isotopes.

\section{Physical Measurements}

Infrared spectra were recorded on a JASCO FT-IR 460 plus spectrophotometer in the range of $4000-400 \mathrm{~cm}^{-1}$ at 298 $\mathrm{K}$. Thermalanalysis (TG-DTA) was performed on a Rigaku TG8120 and $\alpha$-alumina was used as the reference sample, where the heating rate was $10 \mathrm{~K} \mathrm{~min}^{-1}$ in the range of 313$673 \mathrm{~K}$. The magnetic properties were measured with a Quantum Design MPMS-XL superconducting quantum interference device (SQUID) magnetometer at $0-50000 \mathrm{G}$ at $5 \mathrm{~K}$ and at $5-300 \mathrm{~K}$ at $5000 \mathrm{G}$. The Fe2p $\mathrm{p}_{3 / 2}$ and $2 \mathrm{p}_{1 / 2} \mathrm{XAS}$ (soft X-ray absorption spectra) were measured at KEK PF BL-19B under variable temperature. The spectra were corrected by the standard Au sample.

\section{X-ray Crystallography}

Green-yellow, yellow, or (pale) brown prismatic single crystals were glued on top of a glass fiber and coated with a thin layer of epoxy resin to measure the diffraction data. The $\mathrm{X}$-ray intensities were measured at various temperature with graphite-monochromated Mo K $\alpha$ radiation $(\lambda=0.71073 \AA)$ on a Bruker APEX2 CCD diffractometer. The structures were solved by direct methods using SHELXS97 [13] and 
expanded by Fourier techniques in a SAINT program package [14] (including SHELXTL version). The structures were refined on $\mathrm{F}^{2}$ anisotropically for non-hydrogen atoms by fullmatrix least-square methods with SHELXL97 [13]. Empirical absorption corrections were applied by a program SADABS [15]. All the non-hydrogen atoms were refined anisotropically. The hydrogen atoms were included in geometrically calculated position and refined by using riding model. The bad results in refinement are mainly due to thermal vibration of oxygen atoms of crystalline water or radiation damage.

Summary of crystallographic data of selected compounds determined complete crystal structures are as follows:

Crystallographic data for CeFeHH [CCDC 798466]. $T=$ $100 \mathrm{~K}, 0.16 \times 0.11 \times 0.10 \mathrm{~mm}, \mathrm{C}_{18} \mathrm{H}_{36} \mathrm{CeFeN}_{10} \mathrm{O}_{8}$, monoclinic, $P 2{ }_{1} / n, a=17.671(3) \AA, b=8.8685(14) \AA, c=19.605(3) \AA$, $\beta=95.059(2)^{\circ}, V=3055.4(8) \AA^{3}$, and $Z=4, D_{c}=1.558$ $\mathrm{Mgm}^{-3}, \mu=2.000 \mathrm{~mm}^{-1}, R_{l}=0.0413, w R_{2}=0.1068(3613$ reflections), $S=0.777$.

Crystallographic data for CeFeHH [CCDC 798467]. $T=$ $150 \mathrm{~K}, 0.16 \times 0.11 \times 0.10 \mathrm{~mm}, \mathrm{C}_{18} \mathrm{H}_{36} \mathrm{CeFeN}_{10} \mathrm{O}_{8}$, monoclinic, $P 2{ }_{1} / n, a=17.564(2) \AA, b=8.8953(10) \AA, c=19.869(2) \AA$, $\beta=95.8020(10)^{\circ}, V=3088.4(6) \AA^{3}$, and $Z=4, D_{c}=1.541$ $\mathrm{Mgm}^{-3}, \mu=1.978 \mathrm{~mm}^{-1}, R_{1}=0.0340, w R_{2}=0.0938(5364$ reflections), $S=0.733$.

Crystallographic data for CeFeHH [CCDC 798468]. $T=$ $250 \mathrm{~K}, 0.16 \times 0.11 \times 0.10 \mathrm{~mm}, \mathrm{C}_{18} \mathrm{H}_{36} \mathrm{CeFeN}_{10} \mathrm{O}_{8}$, monoclinic, $P 2_{1} / n, a=17.594(2) \AA, b=8.9169(11) \AA, c=19.966(3) \AA$, $\beta=95.744(2)^{\circ}, V=3116.7(7) \AA^{3}$, and $Z=4, D_{c}=1.527$ $\mathrm{Mgm}^{-3}, \mu=1.960 \mathrm{~mm}^{-1}, R_{l}=0.0340, w R_{2}=0.0952(4937$ reflections), $S=0.759$.

Crystallographic data for CeFeDH [CCDC 798465]. $T=$ $150 \mathrm{~K}, 0.34 \times 0.34 \times 0.23 \mathrm{~mm}, \mathrm{C}_{18} \mathrm{H}_{36} \mathrm{CeFeN}_{10} \mathrm{O}_{8}$, monoclinic, $P 2{ }_{1} / n, a=17.659(2) \AA, b=8.8636(12) \AA, c=19.912(3) \AA$, $\beta=96.017(2)^{\circ}, V=3052.8(7) \AA^{3}$, and $Z=4, D_{c}=1.559$ $\mathrm{Mgm}^{-3}, \mu=2.001 \mathrm{~mm}^{-1}, R_{1}=0.0303, w R_{2}=0.0921(5745$ reflections), $S=0.769$.

Crystallographic data for GdFeHH [CCDC 798469]. $T=$ $293 \mathrm{~K}, 0.34$ x 0.34 x $0.23 \mathrm{~mm}, \mathrm{C}_{18} \mathrm{H}_{36} \mathrm{FeGdN}_{10} \mathrm{O}_{8}$, monoclinic, $P 2{ }_{1} / n, a=17.6109(17) \AA, b=8.8563(9) \AA, c=19.7915(19)$ $\AA, \beta=96.1350(10)^{\circ}, V=3069.2(5) \AA^{3}$, and $Z=4, D_{c}=1.588$ $\mathrm{Mgm}^{-3}, \mu=2.669 \mathrm{~mm}^{-1}, R_{1}=0.0552, w R_{2}=0.1576(5948$ reflections), $S=1.392$.

Crystallographic data for GdFeHH [CCDC 798470]. $T=$ $90 \mathrm{~K}, 0.32 \times 0.30 \times 0.28 \mathrm{~mm}, \mathrm{C}_{18} \mathrm{H}_{36} \mathrm{FeGdN}_{10} \mathrm{O}_{8}$, monoclinic, $P 2_{1} / n, a=17.566(3) \AA, b=8.7966(13) \AA, c=19.483(3) \AA$, $\beta=96.281(2)^{\circ}, V=2992.6(8) \AA^{3}$, and $Z=4, D_{c}=1.628$ $\mathrm{Mgm}^{-3}, \mu=2.737 \mathrm{~mm}^{-1}, R_{1}=0.0811, w R_{2}=0.2119(3574$ reflections), $S=1.392$.

Crystallographic data for NdFeDD [CCDC 798471]. $T=$ $173 \mathrm{~K}, 0.15 \times 0.10 \times 0.10 \mathrm{~mm}, \mathrm{C}_{18} \mathrm{H}_{36} \mathrm{FeN}_{10} \mathrm{NdO}_{8}$, monoclinic, $P 2{ }_{1} / n, a=17.5568(8) \AA, b=8.8626(4) \AA, c=19.8079(10)$ $\AA, \beta=95.8720(10)^{\circ}, V=3065.9(3) \AA^{3}$, and $Z=4, D_{c}=1.561$ $\mathrm{Mgm}^{-3}, \mu=2.202 \mathrm{~mm}^{-1}, R_{1}=0.0284, w R_{2}=0.0673(5887$ reflections), $S=1.050$.

Crystallographic data for NdFeDH [CCDC 798472]. $T=$ $173 \mathrm{~K}, 0.10 \times 0.10 \times 0.10 \mathrm{~mm}, \mathrm{C}_{18} \mathrm{H}_{36} \mathrm{FeN}_{10} \mathrm{NdO}_{8}$, monoclinic, $P 2_{1} / n, a=17.5517(11) \AA, b=8.8653(5) \AA, c=19.8248(12)$
$\AA, \beta=95.8370(10)^{\circ}, V=3068.8(3) \AA^{3}$, and $Z=4, D_{c}=1.560$ $\mathrm{Mgm}^{-3}, \mu=2.200 \mathrm{~mm}^{-1}, R_{1}=0.0272, w R_{2}=0.0664(5995$ reflections), $S=1.126$.

Crystallographic data for NdFeHD [CCDC 798473]. $T=$ $173 \mathrm{~K}, 0.58 \times 0.18 \times 0.10 \mathrm{~mm}, \mathrm{C}_{18} \mathrm{H}_{36} \mathrm{FeN}_{10} \mathrm{NdO}_{8}$, monoclinic, $P 2_{1} / n, a=17.5618(11) \AA, b=8.8625(6) \AA, c=19.8013(13)$ $\AA, \beta=95.8800(10)^{\circ}, V=3065.7(3) \AA^{3}$, and $Z=4, D_{c}=1.561$ $\mathrm{Mgm}^{-3}, \mu=2.202 \mathrm{~mm}^{-1}, R_{1}=0.0241, w R_{2}=0.0642(6221$ reflections), $S=1.195$.

Crystallographic data for NdFeHH [CCDC 798474]. $T=$ $293 \mathrm{~K}, 0.15 \times 0.09 \times 0.09 \mathrm{~mm}, \mathrm{C}_{18} \mathrm{H}_{36} \mathrm{FeN}_{10} \mathrm{NdO}_{8}$, monoclinic, $P 2_{1} / n, a=17.615(6) \AA, b=8.906(3) \AA, c=19.934(7) \AA$, $\beta=95.966(7)^{\circ}, V=3110(2) \AA^{3}$, and $Z=4, D_{c}=1.539 \mathrm{Mgm}^{-3}$, $\mu=2.170 \mathrm{~mm}^{-1}, R_{l}=0.0399, w R_{2}=0.0829$ (4994 reflections), $S=0.992$.

Crystallographic data for NdFeHH [CCDC 798475]. $T=$ $100 \mathrm{~K}, 0.15 \times 0.09 \times 0.09 \mathrm{~mm}, \mathrm{C}_{18} \mathrm{H}_{36} \mathrm{FeN}_{10} \mathrm{NdO}_{8}$, monoclinic, $P 2_{1} / n, a=17.674(2) \AA, b=8.8249(10) \AA, c=19.537(2) \AA$, $\beta=96.147(2)^{\circ}, V=3029.6(6) \AA^{3}$, and $Z=4, D_{c}=1.580$ $\mathrm{Mgm}^{-3}, \mu=2.228 \mathrm{~mm}^{-1}, R_{1}=0.0323, w R_{2}=0.0676(5469$ reflections), $S=1.034$.

Crystallographic data for SmFeHH [CCDC 798477]. $T=100 \mathrm{~K}, 0.67 \times 0.19 \times 0.07 \mathrm{~mm}, \mathrm{C}_{18} \mathrm{H}_{36} \mathrm{FeN}_{10} \mathrm{O}_{8} \mathrm{Sm}$, monoclinic, $P 2_{1} / n, a=17.649(3) \AA, b=8.8075(16) \AA$, $c=19.544(4) \AA, \quad \beta=96.207(2)^{\circ}, V=3020.1(10) \AA^{3}$, and $Z=4, D_{c}=1.598 \mathrm{Mgm}^{-3}, \mu=2.460 \mathrm{~mm}^{-1}, R_{l}=0.0455, w R_{2}=$ 0.1187 (5458 reflections), $S=0.862$.

\section{RESULTS AND DISCUSSION}

\section{Temperature Dependence of XAS}

In general, supramolecular chemistry of crystalline materials states that non-covalent bonds such as coordination bonds and hydrogen bonds may show flexibility in crystals. We examined flexibility of crystals depending on temperature for coordination bonds (with XAS) and hydrogen bonds (with magnetic properties and TG-DTA) besides crystal structure determination.

The XAS of $\mathrm{Fe} 2 \mathrm{p}_{3 / 2}$ peak at $715 \mathrm{eV}$ and $\mathrm{Fe} 2 \mathrm{p}_{1 / 2}$ peak at $725 \mathrm{eV}$ were measured for $\mathbf{C e F e H H}$ at 70 and $298 \mathrm{~K}$, CeFeDH at 30, 70, 100, 150, and $200 \mathrm{~K}$, GdFeHH at $298 \mathrm{~K}$, GdFeDH at 30, 65, 100, 150, 200, and $250 \mathrm{~K}$, SmFeHH at 70 and 298 K, and SmFeDH at 298 K. Similar to NdFeHH. All data are characteristic to a low-spin Fe(III) ion. Neither isotope effect nor substitution of lanthanide ions did not affect on electronic states of Fe(III) ions in crystals.

\section{Magnetic Properties}

Magnetic properties may indicate not only superexchange interaction between Fe(III) and Ln(III) ions but also intermolecular hydrogen bonds as paths of magnetic interactions. At high temperature region, obvious discrepancy (less than the contribution of $s=1 / 2$ ) due to isotope effect among LnFeHH, LnFeDH, and $\mathbf{L n F e O H}$ could be found for $\mathbf{L n}=\mathbf{C e}, \mathbf{S m}$, and $\mathbf{G d}$. Although the order of the $\chi_{M} \mathrm{~T}$ values at the same temperature is GdFeHD ( > GdFeDD > GdFeHH > GdFeDH >) GdFeOH, the order is not same for CeFe or SmFe. Which suggests the reason for this differences are not electronic states of $\mathrm{Fe}(\mathrm{III})$ but intermolecular hydrogen bonds (Figs. S1 and S2). 


\section{IR Spectra}

Unfortunately, IR spectra exhibit little difference caused by isotope effect as $\mathrm{O}-\mathrm{H}$ bands, which associate with hydrogen bonds. On the contrary, predominant bands at 2127 , 2121, 2127, and $2020 \mathrm{~cm}^{-1}$ for CeFe, NdFe, SmFe, and GdFe, respectively, exhibit clear difference caused by metal substitution as cyanide bands.

\section{TG-DTA}

However, strength of hydrogen bonds may also vary temperature losing water molecules of isotopes, which can be detected as an endothermal peak with weight loss of TGDTA. Actually, shift of the temperature was observed for NdFeHH, NdFeHD, NdFeDH, and NdFeDD [6]. For new compounds, the temperature was observed at $378 \mathrm{~K}$ for CeFeHH, $393 \mathrm{~K}$ for $\mathbf{C e F e D H}$ and $\mathbf{C e F e O H}$, at $388 \mathrm{~K}$ for GdFeHH, GdFeDD, and GdFeOH and $393 \mathrm{~K}$ for GdFeDH, and at $388 \mathrm{~K}$ for SmFeHH and $393 \mathrm{~K}$ for SmFeDH. However, the relationship between mass numbers and the temperature are not clear (Fig. S3) in contrast to clear differences of the temperature caused by isotope effect.

\section{Crystal Structures}

Overall crystal structures of present study are isostructural to ones reported $[1,2]$ and they are deposited in CCDC. Hereafter we discuss important points about negative thermal expansion only.

Fig. (1) exhibits temperature dependence of cell parameters for NdFeHH, NdFeHD, NdFeDH, and NdFeDD. Along the crystallographic a axis, novel anisotropic negative thermal expansion [16] was observed at 100-125 K and 125$165 \mathrm{~K}$, respectively. Moreover, zero or small thermal expan-

\section{$\mathrm{NdFeHH}$}
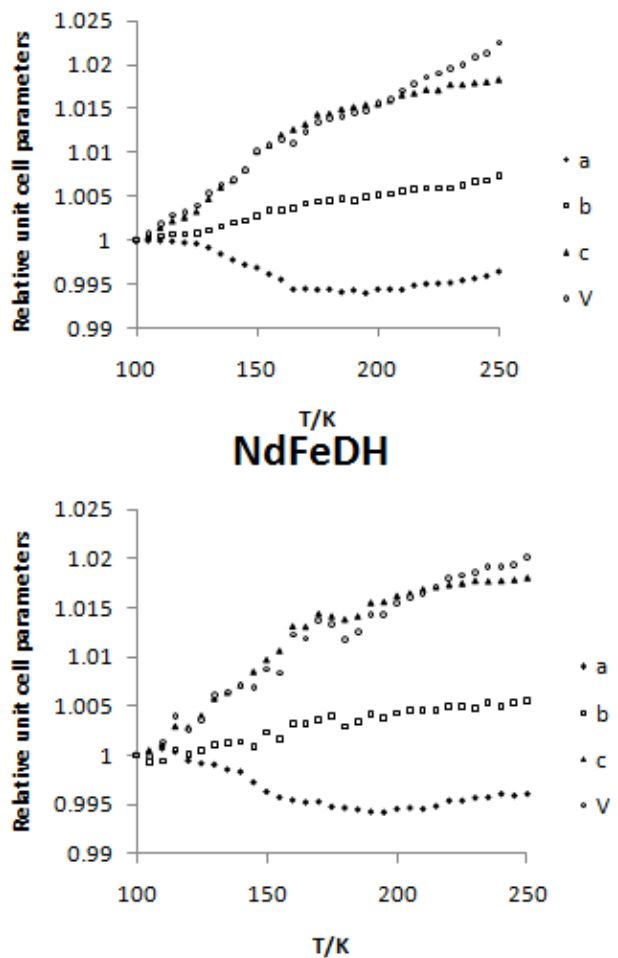

sion was observed at $165-210 \mathrm{~K}$, and positive thermal expansion was observed at 210-250 K. The tendency of curves was same for NdFeHH, NdFeHD, NdFeDH, and NdFeDD and isotope effect resulted in slope of curves rather than the temperature. To our knowledge, this is the first report on isotope effect of negative thermal expansion associate with intermolecular hydrogen bonds [17].

By isotope effect, slight (not exactly statistical) geometrical deviation appeared at Nd1-O2 (2.429(3) ̊), Fe1-C1

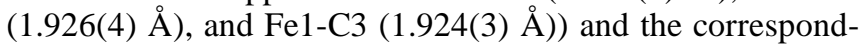
ing (hydrogen) bond distances and angles for NdFeHH at 173 K comparing with NdFeHD, NdFeDH, and NdFeDD having relatively weak hydrogen bonds. No other significant deviation could be observed for other geometric parameters. Unfortunately, complete geometries around hydrogen bonds could not be revealed even by preliminary measurements of neutron crystal structure analysis (JAEA JRR-3 BIX-3) for NdFeDH at room temperature. By temperature effect, NdFeHH at $100 \mathrm{~K}$ and $293 \mathrm{~K}$ indicates significant deviation around coordination bond of Fe1-C2 of 1.945(3) and 1.935(4) $\AA$ and cyanide ligand $\mathrm{C} 2-\mathrm{N} 2$ of $1.152(4)$ and 1.148(6) А, respectively. By supporting other physical measurements, crystal structures show that novel anisotropic negative thermal expansion is attributed to flexible intermolecular hydrogen bonds in crystals.

Substitution of lanthanide ions resulted in similar isotope effect. For example, Ce1-O2 (2.468(3), 2.460(2), and

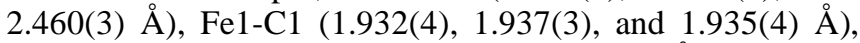
and Fe1-C3 (1.920(4), 1.937(3), and 1.934(4) $\AA$ )) at $120 \mathrm{~K}$ for $\mathrm{CeFeHH}, \mathrm{CeFeDH}$, and $\mathrm{CeFeOH}$, respectively. Only the relative values of the crystallographic a axis against 100 $\mathrm{K}$ in important temperature region are plotted in Fig. (2).
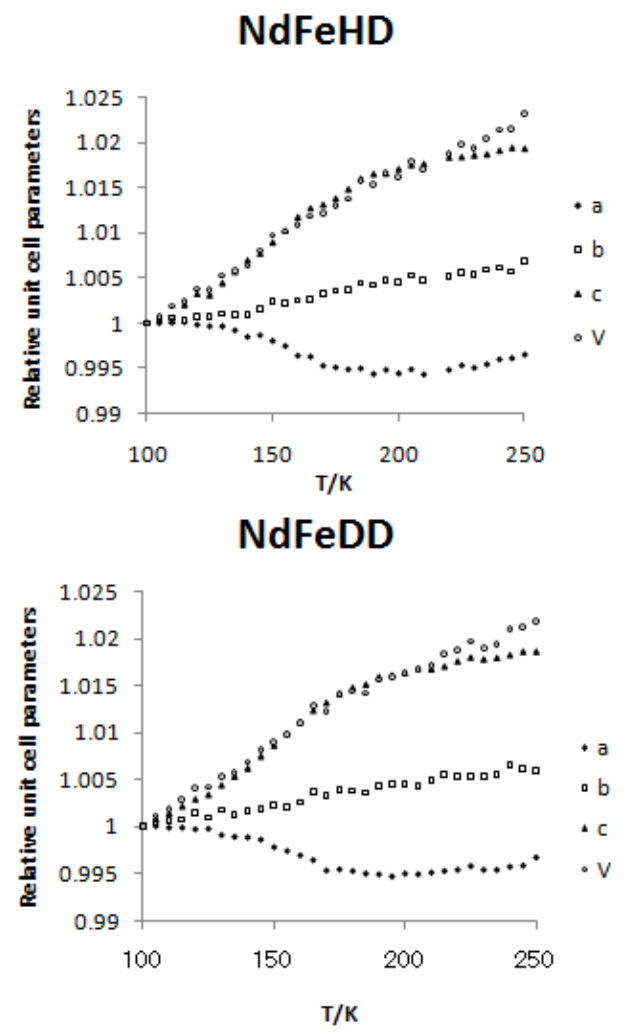

Fig. (1). Temperature dependence of cell parameters (relative values to $100 \mathrm{~K}$ ) for NdFeHH, NdFeHD, NdFeDH, and NdFeDD. 


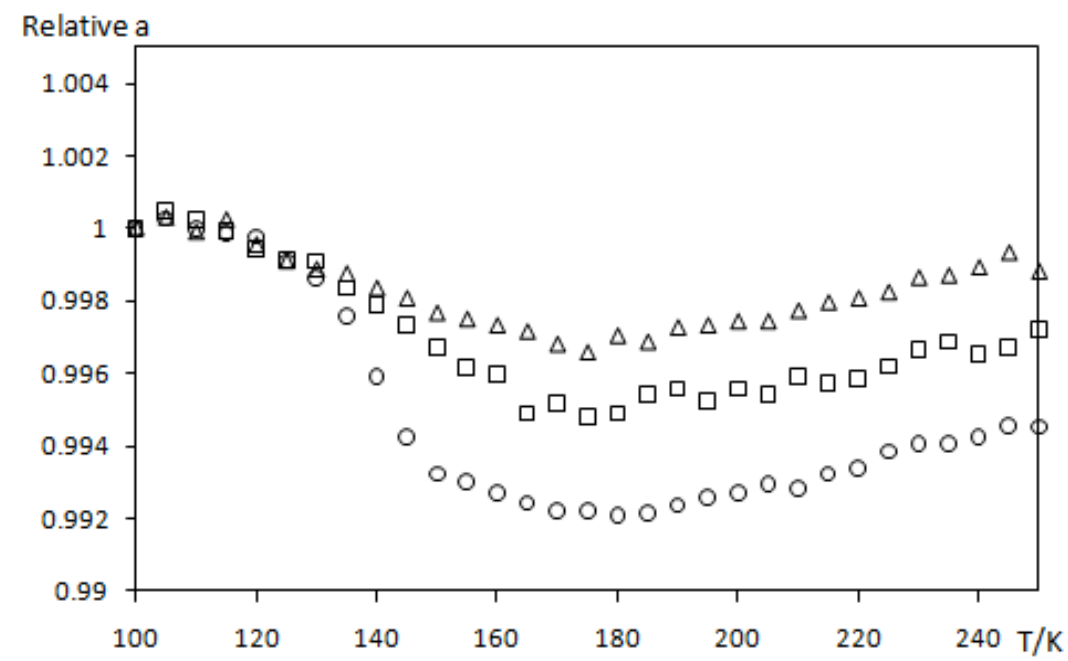

Fig. (2). Temperature dependence of the a axis (relative values to $100 \mathrm{~K}$ ) for $\mathbf{C e F e H H}$ (circles), SmFeHH (squares), and GdFeHH (triangles).

Similar to isotope effect in Fig. (1), anisotropic negative thermal expansion was also observed for CeFeHH, SmFeHH, and GdFeHH. The slope of curves (rather than temperature) is obvious difference of negative thermal expansion by substitution of lanthanide ions.

\section{CONCLUSION}

We have successfully found negative thermal expansion for some $\mathrm{Ln}(\mathrm{DMF})_{4}\left(\mathrm{H}_{2} \mathrm{O}\right)_{3} \mathrm{Fe}(\mathrm{CN})_{6} \cdot \mathrm{H}_{2} \mathrm{O}$ complexes. Indeed, extremely long semi-coordination bonds of $\mathrm{Cu}$ (II) complexes [18-22] sometimes have potential advantage to form flexible crystals against external temperature changes, which is anisotropic along the Jahn-Teller axis [23-25]. However, the present systems show anisotropically negative thermal expansion caused by not coordination bonds around lanthanide nor iron atoms but intermolecular hydrogen bonds with isotope effect for the first time.

\section{SUPPLEMENTARY DATA}

Supplementary material is available on the publishers web site along with the published article.

\section{ACKNOWLEDGEMENTS}

We are gratefully acknowledged to the Materials Design and Characterization Laboratory, Institute for Solid State Physics, the University of Tokyo for the use of the SQUID facilities and KEK-PF BL-19B (2008G528) for soft X-ray absorption spectroscopy of synchrotron radiation.

\section{REFERENCES}

[1] Figuerola A, Diaz C, Ribas J, et al. Synthesis and characterization of heterodinuclear $\mathrm{Ln}^{3+}-\mathrm{Fe}^{3+}$ and $\mathrm{Ln}^{3+}-\mathrm{Co}^{3+}$ complexes, bridged by cyanide ligand $\left(\mathrm{Ln}^{3+}=\right.$ lanthanide Ions. nature of the magnetic interaction in the $\mathrm{Ln}^{3+}-\mathrm{Fe}^{3+}$ complexes. Inorg Chem 2003; 42: 641-9.

[2] Akitsu T, Einaga Y. Structures and XPS studies of several $3 \mathrm{~d}-4 \mathrm{f}$ cyano-bridged $\mathrm{Ln}^{\mathrm{III}}-\mathrm{Fe}^{\mathrm{III}} / \mathrm{Co}^{\mathrm{III}}$ heterometallic complexes. Olyhedron 2006; 25: 2655-62; and references therein.

[3] Li G, Akitsu T, Sato O, Einaga Y. Photoinduced magnetization of the Cyano-Bridged 3d-4f heterobimetallic assembly $\mathrm{Nd}(\mathrm{DMF})_{4}$ $\left.\left(\mathrm{H}_{2} \mathrm{O}\right)_{3}(\mu-\mathrm{CN}) \mathrm{Fe}(\mathrm{CN})_{5}\right] \cdot \mathrm{H}_{2} \mathrm{O}(\mathrm{DMF}=N, N$-Dimethylformamide $) . \mathbf{J}$ Am Chem Soc 2003; 125: 12396-7.

[4] Svendsen H, Overgaard J, Chevallier M, Collet E, Iversen BB. Photomagnetic switching of the complex $\mathrm{Nd}(\mathrm{dmf})_{4}\left(\mathrm{H}_{2} \mathrm{O}\right)_{3}(\mu$ -
$\left.\mathrm{CN}) \mathrm{Fe}(\mathrm{CN})_{5}\right] \cdot \mathrm{H}_{2} \mathrm{O}$ analyzed by single-crystal X-ray diffraction. Angew Chem Int Ed 2009; 48: 2780-3.

[5] Akitsu T, Einaga Y. Structure of cyano-bridged Eu(III)-Co(III) bimetallic assembly and its application to photophysical verification of photomagnetic phenomenon. Chem Pap 2007; 61: 194-8.

[6] Akitsu T, Kimoto Y, Yamada Y, Nomura K. H/D Isotope effect and magnetic properties of cyanide-bridged $\mathrm{Nd}(\mathrm{III})-\mathrm{Fe}(\mathrm{III})$ complex. Radiochim Acta (in press).

[7] Goodwin AL, Chapman KW, Kepert CJ. Guest-dependent negative thermal expansion in nanoporous prussian blue analogues $\mathrm{M}^{\mathrm{II}} \mathrm{P}$ $\mathrm{t}^{\mathrm{IV}}(\mathrm{CN})_{6} \cdot \mathrm{x}_{\left\{\mathrm{H}_{2} \mathrm{O}\right\}}(0<\mathrm{x}<2 ; \mathrm{M}=\mathrm{Zn}, \mathrm{Cd})$. J Am Chem Soc 2005; 127: $17980-1$.

[8] Goodwin AL, Kennedy BJ, Kepert CJ. Thermal expansion matching via framework flexibility in Zinc dicyanomellates. J Am Chem Soc 2009; 131: 6334.

[9] Goodwin AL, Calleja M, Conterio MJ, et al. Colossal positive and negative thermal expansion in the framework material $\mathrm{Ag}_{3}\left[\mathrm{Co}(\mathrm{CN})_{6}\right]$. Science 2008; 319; 794-7.

[10] Korcok JL, Katz MJ, Leznoff DB. Impact of metallophilicity on "Colossal" positive and negative thermal expansion in a series of isostructural dicyanometallate coordination polymers. J Am Chem Soc 2009; 131: 4866-71.

[11] Falvello LR, Jahn-Teller effects in solid-state co-ordination chemistry. J Chem Soc Dalton Trans 1997; 4463-75.

[12] Halcrow MA. Interpreting and controlling the structures of sixcoordinate copper(II) centres - When is a compression really a compression? Dalton Trans 2003; 4375-84.

[13] Sheldrick GM. A short history of SHELX. Acta Crystallogr A 2008; 64: 112.

[14] Bruker . SMART and SAINT. Bruker AXS Inc., Madison, Wisconsin, USA, 1998.

[15] Sheldrick GM. SADABS. Program for empirical absorption correction of area detector data, University of Gottingen, Germany, 1996.

[16] Haas S, Batlogg B, Besnard C, Schiltz M, Kloc C, Siegrist T. Large uniaial negative thermal expansion in pentacene due to steric hindrance. Phys Rev B 2007; 76: 205203.

[17] Fisher SJ, Helliwell JR. An inivestigation into structural changes due to deuteration Acta Crystallogr A 2008; 64: 359-67.

[18] Sereda O, Stoeckli-Evans H, Dolomanov O, Filinchuk Y, Pattison P. Transformation of a chiral nanoporus bimitallic cyano-bridged framework triggered by dehydration/rehydration. Crystal Growth Des 2009; 9: 3168-78.

[19] Sereda O, Neels A, Stoeckli F, Stoeckli-Evans H, Filinchuk Y. Sponge-like reversible transformation of a bimetallic cyanometallate polymer. Crystal Growth Des 2008; 8: 2307-11.

[20] Sereda O, Neels A, Stoeckli F, Stoeckli-Evans H. Chiral bimetallic assemblies and coordination polymers based on tetracyanonickelate: 
a striking reversible structural transformation. Crystal Growth Des 2008; 8: 3380-4.

[21] Akitsu T, Einaga Y. Extremely long axial $\mathrm{Cu}-\mathrm{N}$ bonds in chiral one-dimensional zigzag cyanide-bridged $\mathrm{Cu}^{\mathrm{II}}-\mathrm{Ni}^{\mathrm{II}}$ and $\mathrm{Cu}^{\mathrm{II}}-\mathrm{Pt}^{\mathrm{II}}$ bimetallic assemblies. Inorg Chem 2006; 45: 9826-33.

[22] Akitsu T, Einaga Y. Tuning of electronic properties of onedimensional cyano-bridged $\mathrm{Cu}^{\mathrm{II}}-\mathrm{Ni}^{\mathrm{II}}, \mathrm{Cu}^{\mathrm{II}}-\mathrm{Pd}^{\mathrm{II}}$, and $\mathrm{Cu}^{\mathrm{II}}-\mathrm{Pt}^{\mathrm{II}}$ bimetallic assemblies by stereochemistry of ligands. Inorg Chim Acta $2008 ; 361: 36-42$.
[23] Akitsu T, Einaga Y, Yoza K. Thermally-accessible lattice strain and local pseudo jahn-teller distortion in various dimensional $\mathrm{Cu}^{\mathrm{II}}-$ $\mathrm{M}^{\mathrm{III}}$ bimetallic cyanide-bridged assemblies. Open Inorg Chem J 2008; 2: 1-10.

[24] Akitsu T, Einaga Y. Thermal and photo-responsibiliry of axial semi-coordination bonds in Copper(II) complex. Bull Chem Soc Jpn 2004; 77: 763-4.

[25] Akitsu T, Sano K. Analogy of van't Hoff relationship for thermallyaccessible lattice strain of Copper(II) complex. Netsu Sokutei 2009; 36: 244-6.

(C) Kimoto et al.; Licensee Bentham Open.

This is an open access article licensed under the terms of the Creative Commons Attribution Non-Commercial License (http://creativecommons.org/licenses/by$\mathrm{nc} / 3.0 /$ ) which permits unrestricted, non-commercial use, distribution and reproduction in any medium, provided the work is properly cited. 